equal frequency in the three groups. In spite of a high incidence of involvement of the hands and feet in the atypical group, the comparatively low proportion of patients in this group giving positive results with Ball's modification of Rose's serum differential agglutination test is evidence that the atypical group is not largely composed of patients with rheumatoid arthritis affecting the spine. The adverse effect of prolonged immobilization in typical ankylosing spondylitis is emphasized.

A total of 275 patients received deep $x$-ray therapy; the proportion much improved after this in the typical group was very significantly higher than in the atypical group. In the typical group, the age or sex of the patient and level of the blood sedimentation rate gave no indication of the probability of improvement after therapy; better results were obtained in patients whose symptoms were of five years' duration or less and in whom radiological changes were confined to the sacroiliac joints. No significant difference was observed in the behaviour of peripheral joints treated alone and those treated concurrently with the spine, suggesting that the effect of deep $x$-ray therapy in ankylosing spondylitis is a local one on irradiated tissues.

Complications of $x$-ray therapy included one case of aplastic anaemia, reactivation of pulmonary tuberculosis in one case, permanent amenorrhoea in 13 of the 47 females treated, and possible acceleration of renal failure in two cases.

Reasons are given for ascribing the poor results from $x$-ray therapy in the atypical group to inclusion of patients with other diseases simulating ankylosing spondylitis.

We are grateful to the many consultants in this region who have allowed us to study their cases during the investigation; to Professor J. H. Kellgren for much advice and helpful criticism; to Dr. Ralston Paterson for provision of facilities for $x$-ray treatment and follow-up of the patients; to Dr. O. Janus, who saw many of these patients originally in the clinic; and to Miss Marion Russell for help with the statistics.

Ball, J. (1950). Lancet, 2, 520. REFERENCES

(1952). Ann. rheum. Dis., 11, 97.

Desmarais. M. H. L. (1953). Ibid., 12. 25

Hare. H. F. (1940). New Engl. J. Med., 223, 702

Hart. F. D., Robinson. K. C., Allchin, F. M., and Maclagan, H. F. (1949) Quart. J. Med.. 18. 217

Bogdanovitch, A., and Nichol, W. D. (1950). Ann. rheum. Dis., 9. 116.

Hilton, G. (1943). Proc. roy. Soc. Med., 36, 608.

Kahlmeter. G. (1930) Brit. J. Actinn-ther., 5. 93.

Kuhns. J. G.. and Morrison, S. L. (1946). New Engl. J. -Med.. 235. 399

Kunkler, P. B., Farr, R. F., and Luxton, R. W. (1952). Brtu. J. Radiol., 25 190.

McWhirter. R. (1945). Ibid., 18. 302.

Mowbray R., Latner, A. L., and Middlemiss, J. H. (1949). Quart. J. Med. 18, 187

Parr. L. J. A., White, P., and Shipton. E. (1951). Med. J. Austr., 1. 544 Polley. H. F.. and Slocumb. C. H. (1947), Ann. Intern. Med.. 26. 240.

Scott. S. G. (1942). A Monograph on Adolescent Spondylitis or Ankylosin Spondylitis. The Early Diagnosis and its Treatment by Wide Field

$X$-ray Irradiation. Oxford Univ. Press, London.
Smyth. C. J., Freyburg, R. H., and Lampe. I. (1941a). J. Amer. med. Ass., 117. 826.

Swaim. L. T. (1939). J. Bone Jt Surg., 21, 983.

Bracken Hill House, The Woods, Northwood, Middlesex, the pioneer hostel of B.R.A. Homes Ltd. (under the aegis of the British Rheumatic Association), is now open. It is designed to meet the needs of industrial workers with early and serious rheumatic conditions for whom bed accommodation at hospitals with rheumatic units is unlikely to be available in the near future. All medical services are provided by Mount Vernon Hospital. Industrial medical officers or the patient's family doctor can apply for accommodation. Cost of beds ranges from $£ 415 \mathrm{~s}$. to $£ 77 \mathrm{~s}$ Further details may be obtained from either Bracken Hill House or the British Rheumatic Association, 11, Beaumont Street, London, W.1.

\section{CONGENITAL VALVES IN THE POSTERIOR URETHRA}

\author{
BY
}

D. INNES WILlIAMS, M.D., M.Chir., F.R.C.S.

Genito-urinary Surgeon, the Hospital for Sick Children, Great Ormond Street

A valvular formation of mucosal folds in the posterior urethra is the most often encountered example of the group of congenital anomalies which cause urethral obstruction. A full pathological and clinical description of the condition was given by Young, Frontz, and Baldwin in 1919, yet the lesion has never been widely recognized nor has a satisfactory routine for diagnosis and treatment emerged. I have had the opportunity of operating upon 14 of these valve cases, and the present observations are based upon the study of this series, and of the records of 21 further cases in which the diagnosis has been confirmed by post-mortem examination at the Hospital for Sick Children. All but one of the 14 cases have been treated during the past two years, and it may be of interest to record that during the same period eight cases with other forms of congenital urethral obstructions and four cases of bladder-neck obstruction in young children have come under treatment.

\section{Their Origin}

In the characteristic form (Young's type 1) a valve is formed on either side of the urethra by a double fold of mucous membrane, the two meeting in the midline sagittal plane of the urethra, leaving only a small channel anteriorly (Fig. 1). The free edges of the valves are continuous above and posteriorly

with ridges connected with the verumontanum ; below and anteriorly they fade out on the urethral wall at approximately the level of the external sphincter.

Faint ridges with a similar disposition are evident in the normal male urethra, and I have observed that in the embryo they first appear at approximately the $50-\mathrm{mm}$. stage. The ridges were exceptionally well developed in a $99-\mathrm{mm}$.

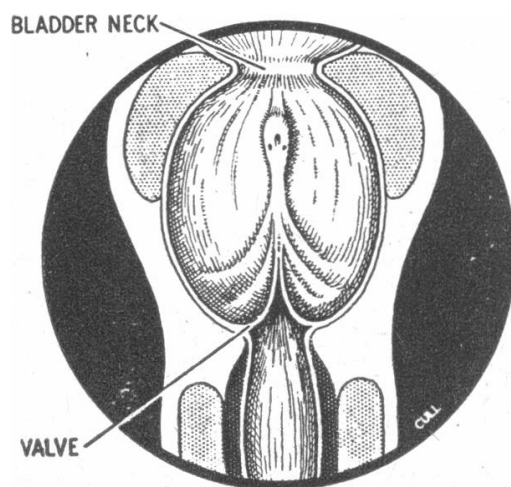

FIG. 1.-Diagram showing the disposition of urethral valves in their most characteristic form. The urethra has been drawn as if it had been opened by a vertical incision of the anterior wall, so that the anterior extremities of the valvular folds are held apart.

embryo which I have examined; they have no discernible function, and after this stage they appear to shrivel spontaneously, but it is clear that it would require only a slight exaggeration of the normal formation with some adhesion of the free edges to bring about the development of an obstructive valve. We are thus dealing with only a minor deviation from the normal, and we should not therefore expect a high instance of multiple congenital anomalies in this disease. In fact, the accompanying abnormalities are chiefly those consequent upon the obstruction.

From this evidence of their origin, it will be manifest that congenital valves will constitute an obstruction to the urinary passages almost from the time that urine is first formed and long before the complete differentiation of the nephrons. A free flow of urine is not, of course, essential 
to the general development of the foetus, and growth can proceed almost normally in the complete absence of kidneys ; nevertheless, despite conflicting views, it does seem that urine secretion is a normal foetal activity and that urinary obstruction produces hypertrophy of the detrusor, sacculation of the bladder wall, dilatation of the ureters, and hydronephrosis whether it occurs in the foetus or in old age. The urinary tracts of infants dying from this disease during the first few days of life show all the changes associated with long-standing retention of urine, but it is characteristic of the very early obstructions that they cause relatively less bladder distension with relatively greater dilatation of the ureters, and that differentiation of the nephrons is interfered with so that the cortex of the kidney may contain cysts which show no evident connexion with the renal pelvis.

may prove overwhelming. The newer sulphonamides and antibiotics can, however, sometimes sterilize the urine even in the presence of an obstruction, and the rapid amelioration of symptoms may then suggest that no further investigation is required. In two of my cases the bladder and kidneys had been palpably distended during an episode of urinary infection at the ages of 1 month and 2 years respectively, yet because apparently normal micturition was re-established after sterilization of the urine the clinician in charge had felt that no organic obstruction could be present. As a result the children were left, one for three months, the other for seven years, before receiving surgical treatment, and in the latter irreparable renal damage had occurred.

Valvular obstruction is for the most part a slowly progressive disorder ; sometimes, as in prostatic disease, there is an

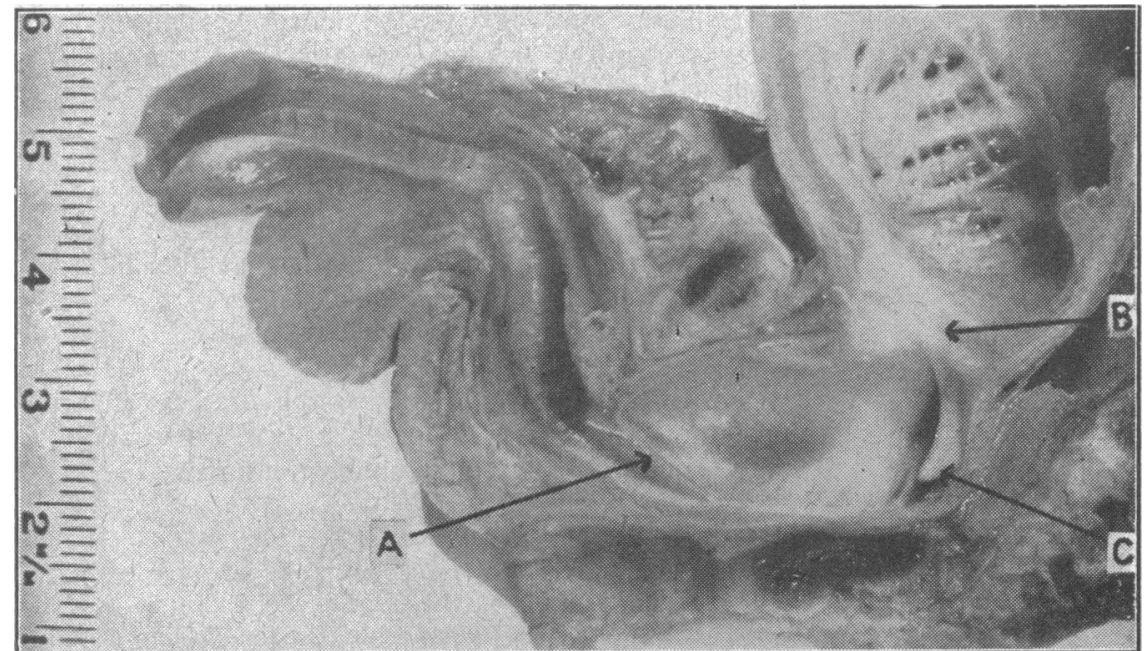

Fig. 2. - Sagulual section through the bladder and urethra of an infant dying on the third day of life (from the Museum of the Hospital for Sick Children, Great Ormond Street). The enormous dilatation of the posterior urethra is clearly shown, and there is a well-marked valvular fold. A, valve; $B$, bladder neck; C, verumontanum.

These observations apply to all types of congenital infravesical obstruction, but the situation of the valves leads to certain peculiar features. The posterior urethra becomes dilated and considerably elongated (Fig. 2), but the bladder neck remains as a well-defined constriction until a very late stage. The internal sphincter is essentially a condensation of detrusor muscle fibres, and it appears that a general hypertrophy of the bladder muscle must be inevitably associated with bladder-neck hypertrophy.

\section{Clinical Features}

On the clinical side, urethral valves present either because of disorders of micturition-incontinence, frequency, haematuria - or because of a deterioration of renal function-failure to thrive, dwarfism, or renal rickets.

Valves scarcely ever cause acute retention. Some urine is always able to dribble away, even though the rapidity of onset of bladder distension may have been sufficient to cause pain. Failure to pass urine during the first few days of postnatal existence is, of course, usually due to dehydration and oliguria, but if the bladder is found distended it is much more likely that the obstruction is an obliteration of the urethra rather than a valve. Overflow incontinence is in fact the most characteristic disturbance of micturition : urine is never passed in a good stream, but the frequent and difficult passage of small quantities or a continuous dribbling makes the child always wet. An infant who is found never to be dry has always some organic disease, and if we can be sure of the truth of this history a most careful investigation is imperative. In older children the incontinence is less easily distinguishable from functional enuresis, though it is usually diurnal as well as nocturnal, and its tendency is to become progressively more severe.

The onset of infection leads to an exacerbation of the obstruction and in the presence of already damaged kidneys exacerbation of obstruction for no very obvious reason, and in such cases pain may be a feature. One of my cases was sent to hospital as a possible case of intussusception. and another, who had a large diverticulum, suffered abdominal pain before micturition.

Renal failure manifests itself in a variety of ways, and it is a curious fact that the cases with the most severe signs are often those with comparatively minor disturbances of micturition. During the first few weeks of life vomiting is much the most common presenting sign, and the infant is often suspected of pyloric stenosis until examination reveals distension of the bladder and a continuous dribble of urine. In later infancy and childhood general ill-health and susceptibility to infection or dwarfism may lead to investigation of renal function. Hypovitaminosis-D rickets is now such a rare disease in this country that the presence of a rachitic deformity must always suggest the need for urological investigation.

\section{Diagnosis}

Often the observation of an overdistended bladder and of a dribbling incontinence leaves little doubt concerning the presence of a urinary obstruction, and in a few cases the rectal palpation of a full posterior urethra gives assistance in locating the lesion, but the exact diagnosis of urethral valves can never be made on purely clinical grounds. Certain other causes of chronic bladder distension may, of course, be eliminated by clinical examination: the neurological disorders, for instance, are almost invariably accompanied by a recognizable spinal lesion, by sacral anaesthesia, and by paralysis of the anal sphincter. A meatal stenosis, or occasionally a diverticulum of the anterior urethra, may be seen on examination of the penis, but there remain many other obstructive lesions which can be identified only by radiological and endoscopic methods. Recently encountered examples of such lesions include a congenital stenosis of the membranous urethra, a diaphragmatic obstruction above the verumontanum, a duplication of the anterior urethra, and a ureterocele prolapsing through the bladder neck. Bladder-neck obstruction (Marion's disease) is perhaps the disorder most likely to cause confusion, particularly since hypertrophy of the bladder-neck muscle is the usual concomitant of any congenital obstruction lower down the urethra. This difficulty is illustrated by the following case.

A boy of $3 \frac{1}{2}$ years was transferred from an orthopaedic hospital where he had been receiving treatment for a suspected tuberculous lesion of the left femoral neck. He was immobilized on a frame with traction on the left leg, and a wide-bore needle had been inserted suprapubically to drain a chronically distended bladder. 
His blood urea was $68 \mathrm{mg}$. per $100 \mathrm{ml}$. and an intravenous pyelogram showed no shadow in either renal area. His position on the frame rendered endoscopy impossible, and the replacement of the needle by some more satisfactory form of drainage seemed imperative. In performing the cystostomy, however, I palpated the bladder neck, which was clearly hypertrophied and resisted dilatation. A generous wedge of tissue was therefore resected from the posterior lip upon the tentative diagnosis of Marion's disease, but I was disappointed to find

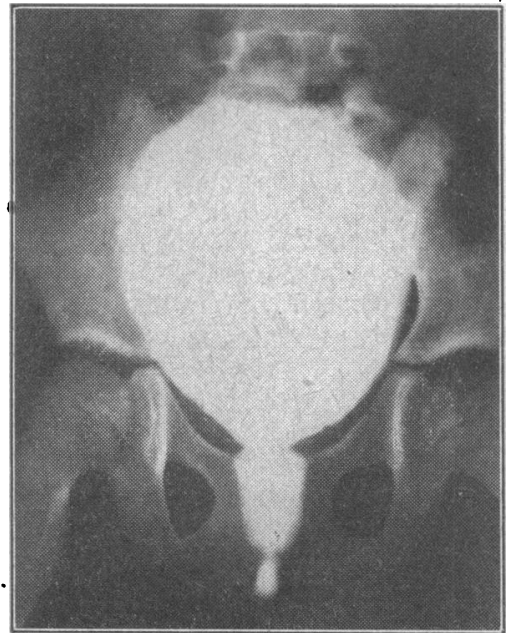

FIG. 3.-Micturating cystogram in a boy of 8 years with a palpably distended bladder and incontinence of urine by day and night since age of 5 . The dilated posterior urethra is evident; urethroscopy confirmed the presence of urethral valves. Treated by endoscopic resection with satisfactory results. that no improvement resulted from this operation and that micturition was not re-established. In the meantime, the child had been seen by Mr. E. I. Lloyd, who gave his opinion that the bone lesion was not tuberculous, and that immobilization was not required. A urethroscopy could therefore be undertaken and valvular folds below the verumontanum were then clearly identified. A retropubic valvulotomy was performed and the child subsequently recovered normal micturition wit hout residual urine. A year later the blood urea was $38 \mathrm{mg}$. per $100 \mathrm{ml}$ and the pyelogram demonstrated a satisfactory recovery of

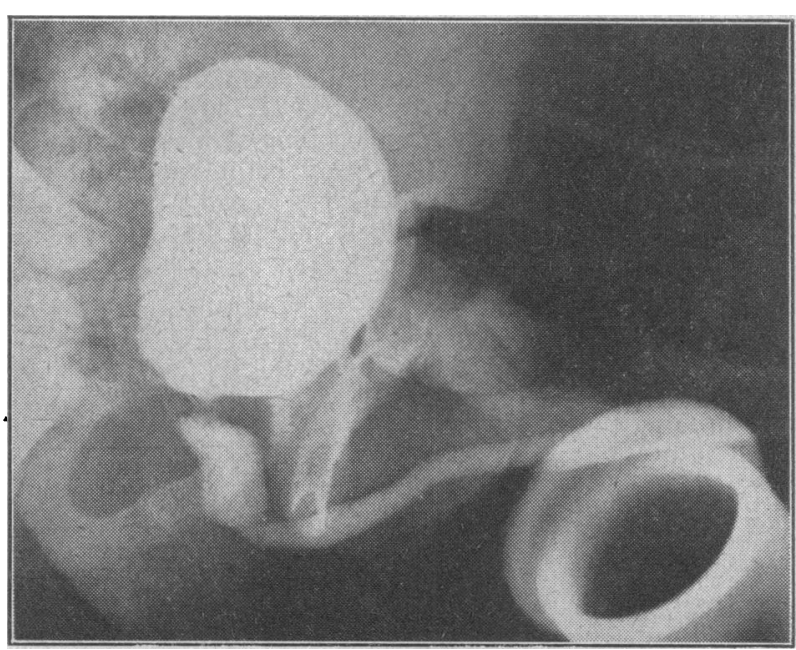

FIG. 4.-Micturating cystogram (oblique view) in a boy of 7 with lifelong dribbling incontinence of urine. Residual urine $6 \mathrm{oz}$. (170 mi.). Endoscopic resection has eliminated the residual urine and he is now continent.

renal function although some dilatation of the upper urinary tract remained.

The most important radiological investigation is the micturating cystogram. A catheter is passed, and the residual urine is drawn off and replaced by a rather larger volume of a $15 \%$ diodone solution. The catheter is then withdrawn and exposures are made during micturition (Figs. 3 and 4). These films may show trabeculation of the bladder, the presence of vesical diverticula, reflux into dilated ureters, and dilatation and elongation of the posterior urethra. It should be noticed that unless micturition is actually taking place the urethra may be shut off from the bladder by the hypertrophied internal sphincter, so that it is either not filled at all or contains only a trickle of opaque fluid, giving no true idea of its dimensions. In the young baby in whom micturition is not possible, manual expression of the bladder contents under anaesthesia is often an adequate substitute, but this does not hold good for the older children (Fig. 5). The cysto-urethrogram shows the exact site of the obstruction, and occasionallv the actual outline of the valvular folds can be seen, but often the differentiation of the valves from congenital stenosis is impossible.

Cystoscopy and urethroscopy give more detailed information but require special instruments and much more experience for their interpretation. In the infant the instruments must be introduced via a perineal urethrostomy, but, provided this is performed, no particular difficulty should be en-

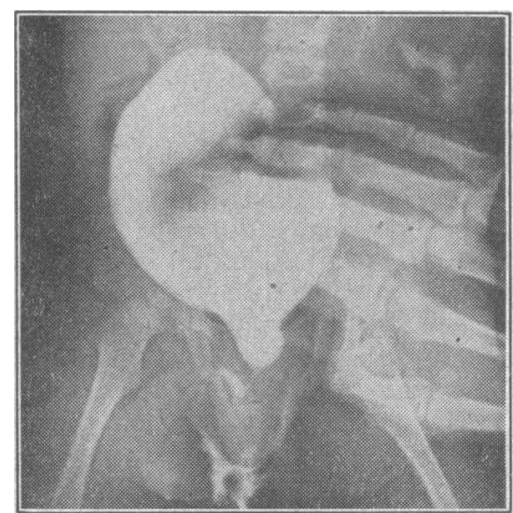

Fig. 5.-Expression cystogram in a boy of 10 months with a blood urea of $212 \mathrm{mg}$. per $100 \mathrm{ml}$. Dilatation of the posterior urethra is clearly present, but urethroscopy showed only a congenital stenosis of the membranous region, and there has been a steady improvement, with continuing fall of blood urea, on intermittent dilatation. countered. I have

recently urethroscoped a male infant of $\mathbf{1 0}$ days in this way. The cystoscope alone will reveal trabeculation of the bladder and the presence or absence of diverticula. The urethroscope, and preferably one which gives a view directly ahead, is required to identify the nature of the obstruction.

\section{Management}

The problems encountered in management vary according to the manifestation of the disease. In the infant with a palpably distended bladder, dribbling micturition, and a degree of renal failure, an operation for relief of urinary obstruction will clearly be required, but considerable caution must be exercised in preparing for this operation. It should be realized that drainage of the bladder is not the most urgent need in such a case; the dangers to life are from supervening infection and from a sudden biochemical disturbance, both of which may in fact be precipitated by catheterization. As in the elderly prostatic, the catheter, even when passed with stringent asepsis, may introduce an infection which initiates a rapidly fatal pyelonephritis. Particularly is it dangerous to empty a chronically distended bladder and then allow it to fill up again with a large residual urine. A clear idea of the degree of renal failure and of the presence or absence of other biochemical disturbances is the first essential. The blood urea is the most helpful single investigation, but deceptively high values may be observed if the child is dehydrated, and the estimation should be repeated after adequate fluid has been given.

The range of specific gravity of the urine often gives a useful indication of renal function; commonly the kidneys in severe cases are only capable of producing urine with a specific gravity of 1001 to 1006 . Estimations of the bicarbonates, chlorides, sodium, and potassium are important in regulating the fluid and electrolyte requirements, and in long-standing cases with bone changes calcium and phosphorus studies are also required. Once instrumentation has been resorted to, adequate drainage of the urinary tract must be established and, if possible, a definitive treatment carried out. My present routine in such a case is therefore to perform a cystogram and a urethroscopy under anaesthesia, and then, unless the general condition of the child renders it dangerous, to proceed at once to operative removal of the 
valve, leaving in a perineal urethrostomy catheter as drainage. In small children an indwelling urethral catheter is scarcely ever an adequate form of drainage: even apart from the danger of stricture formation in the penile urethra, the lumen of the catheter is so small that it easily becomes obstructed.

In the older child who is being investigated for incontinence but who has no serious renal damage, micturating cystography may safely be performed without preparations for immediate operation, provided prophylactic chemotherapy is employed, and full biochemical study may be omitted. The difficulty here is often to know which incontinent boys to investigate, since there is no infallible rule by which they can be segregated. Children with a palpable bladder, those with a continual dribbling incontinence, and older boys who are wet by day as well as by night will clearly be selected, but all enuretics who show no improvement after a fair trial on ordinary treatment should at least be submitted to urethroscopy.

Routine micturating cystography may also be performed during the investigation of recurrent or mild chronic urinary infection. An acute infection complicating an obstruction requires the immediate administration of an antibiotic, and it has seemed wise to give streptomycin while awaiting the bacteriologist's assessment of the susceptibiiity of the organism. Should there be no response to the antibiotic and if the blood urea is considerably raised, drainage of the urinary tract must be established without delay, and for this purpose a bilateral nephrostomy is far more effective than a suprapubic cystostomy which does not satisfactorily empty the dilated and tortuous ureters.

\section{Operation}

Regarding the technique of operation, I believe that the old method of attempting to rupture the valves by passing instruments downwards from the bladder should be discarded: it involves an open bladder, it allows no opportunity for confirmation of the diagnosis, and, as shown by postmortem examination, often fails in its purpose of destroying the valves. The retropubic operation, in which the urethra is opened by a vertical incision prolonged downwards from the bladder neck to a point well below the verumontanum, can give a beautiful exposure and allows a deliberate surgical removal of the valvular fold, but it is often a prolonged and always a major procedure, it may involve considerable blood loss, and it is a severe tax on a uraemic child. In four cases I have employed an approach through the perineum : the bulb of the urethra is opened up through a longitudinal incision, the membranous region dilated up, and a miniature gorget inserted anteriorly. Then with a flat retractor posteriorly, a sucker, and a headlight the operator is able to get a view of the verumontanum and the valves coming down from it. They can be picked up with a blunt hook and burnt off with the diathermy.

Endoscopic resection, however, constitutes the most satisfactory approach employed so far. The instrument which I have used is an infant version of a simple McCarthy diathermy loop resectoscope, and with it the valvular folds can be scooped off the urethral walls. This type of operation is a comparatively minor procedure which does not place any serious strain on the child, but of course it is never a negligible matter to operate on a case of chronic retention, and the use of the resectoscope must always involve some risk of perforating the urethra, which would lead to a dangerous extravasation of urine, or of damaging the external sphincter and causing permanent incontinence.

\section{Discussion}

In discussing the results and complications of the treatment of urethral valves it must again be emphasized that the majority of these children are suffering from long-standing urinary obstruction with severe renal damage. Indeed, those which present during the first month after birth have scarcely ever sufficient functioning renal tissue for survival. In borderline cases it is too often the surgical intervention which precipitates a rapid deterioration of renal function, either through the introduction of infection or through some other mechanism which we do not understand. Post-operative dehydration is always a danger, since the damaged kidneys put out urine of very low specific gravity and require a large volume of fluid in order to excrete the necessary load of solute.

In one case of congenital obstruction, not in fact a valve, an operation which successfully restored normal micturition was followed some weeks later by the development of a severe renal electrolyte loss of sodium and potassium-a type of salt-losing nephritis-which was ultimately the cause of death. One neonatal case of retention had on admission a biochemical pattern resembling Addison's disease, and it could not be determined for certain whether a renal or an adrenal cause was responsible. Another patient, in whom the electrolyte losses had been carefully followed and found normal, died unexpectedly on the third day with cerebral oedema but without any obvious precipitating cause. The biochemical problems involved in treating the obstructive uropathies are therefore complex and as yet poorly understood. It is in this sphere that we hope to make further progress in the future.

Just as the removal of the obstruction cannot lead to an immediate recovery of renal function because of irreversible changes in the kidneys, so too the urinary passages cannot at once regain their normal function. The ureters are tortuous and elongated, and cannot contract down to their former dimensions; in some cases the kinks and adhesions lead to obstruction in the ureter itself, and in several cases drainage of a dilated and obstructed ureter, or nephro-ureterectomy, has been required after the operation for relief of urethral obstruction. The bladder may be atonic, so that it is unable to empty without residuum even after an otherwise successful operation, and if free reflux into the dilated ureters has been established the bladder contractions will serve to fill these ureters rather than to expel the urine. Thus after micturition urine again flows down into the bladder, and catheterization will demonstrate the presence of an apparently large residuum. The loss of normal sensation in the chronically overdistended bladder is also a troublesome feature, since the child does not notice the filling of his bladder and urine may actually be leaking away before micturition is attempted. This is a matter which is capable of improvement by training, however, and should not be a permanent handicap.

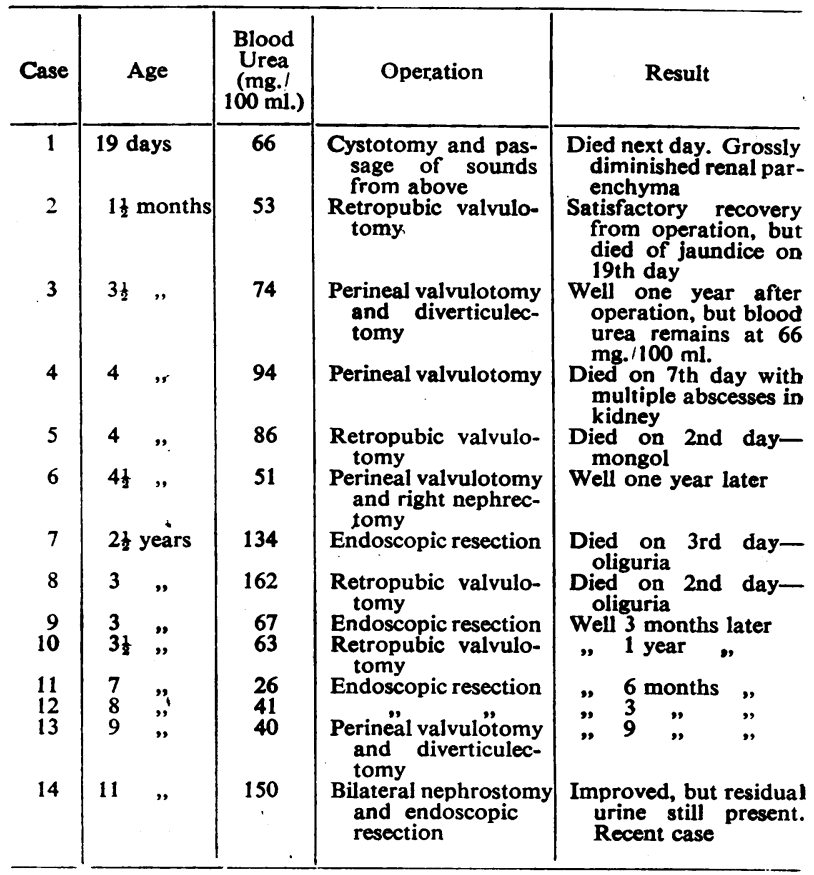


The Table summarizes the 14 cases of urethral valves which have been operated upon: clearly, the results leave a great deal to be desired. The older children are much more likely to survive than the infants, but this merely. indicates that the older children are suffering from a less severe obstruction and in no way contradicts the view that earlier diagnosis will lead to improved results. More careful attention to the urinary abnormalities of the "underthrees" is required if a significant proportion of children with this disease are to grow up to be healthy adults.

ADDENDUM.--In the eight months which have elapsed since this paper was completed the survivors in the series reported have continued to thrive and five additional cases have been treated. Of these, two, aged 9 days and 11 weeks, died of renal failure before operative treatment of the obstruction had been completed; three, aged 3 weeks, 9 months, and 6 years, have made a satisfactory recovery.

My thanks are due to Mr. Twistington Higgins and to other members of the staff of the Hospital for Sick Children, Great Ormond Street, for allowing me to treat their cases, and to Mr. N. Stidolph, of the Whittington Hospital, for inviting me to see the last of the series. Thanks are also due to Mr. Derek Martin and Mr. P. Cull for their assistance with the illustrations.

\section{REFERENCE}

Young. H. H., Frontz, W. A., and Baldwin, J. C. (1919). J. Urol., 3, 289.

\section{CONTINUOUS CAUDAL ANALGESIA}

\section{EXPERIENCES IN THE MANAGEMENT OF DISORDERED UTERINE FUNCTION IN LABOUR*}

BY

G. TREVOR JOHNSON, M.B., M.R.C.O.G., D.A.

First Assistant, Department of Obstetrics and Gynaecology, King's College, Newcastle-upon-Tyne

Prolonged labour which results from incoordinate action of the uterus or cervix is a serious problem which confronts every obstetrician from time to time. The occasional grave consequences to both mother and foetus have resulted in an increasing tendency to terminate such labours by caesarean section when vaginal delivery is delayed after 36 to 48 hours of established labour (Munro Kerr and Chassar Moir, 1949).

The purpose of this paper is to record the experience gained from the therapeutic application of continuous caudal analgesia to the management of this problem. The comments and conclusions are based on a study of 74 cases of discoordinated action of the uterus or cervix which had prolonged the first stage of labour beyond 48 hours. The clinical types treated included hypotonic inertia, hypertonic lower uterine segment inertia, and primary cervical dystocia (Jeffcoate, 1950). The material has been collected from the Department of Obstetrics and Gynaecology at Newcastle-upon-Tyne General Hospital during the past three and a half years, and 22 cases of cervical dystocia reported in a previous publication (Arthur and Johnson, 1952) are included.

Caudal analgesia was originally devised for minor pelvic operations and described simultaneously by Sicard (1901) and Cathelin (1901). The method is therefore not a new one, but Hingson and Edwards (1943) are largely responsible for describing the modern continuous technique and for applying it to obstetric practice, chiefly as a pain-relieving measure. The in-

\footnotetext{
*Condensed from a paper presented to the Newcastle-uponTyne Obstetric Society on December 5, 1952.
}

trinsic difficulties and possible complications of the method, in its present form, however, prejudice its widespread adoption for obstetric analgesia, especially when adequate results are obtainable by simpler means. On the other hand, the satisfactory results achieved by its therapeutic use in the management of disordered uterine function justify a wider trial (Nixon, 1952).

The principle of caudal analgesia in the labouring patient is to block the sacral plexus with a suitable local analgesic agent as it lies within the confines of the sacral canal, and to extend the level of analgesia upwards in the extradural space to the level of the tenth dorsal segment.

By this means both the motor and the sensory connexions to the pelvic floor and perineum arising from the sacral plexus are effectively blocked, together with the visceromotor parasympathetic connexions to the cervix. The upward extension of analgesia to the tenth dorsal segment in the extradural space interrupts the sensory connexions to the fundus uteri which enter the cord at this level, and the uterine action becomes painless. The sympathetic visceromotor fibres of the fundus uteri arising from the cord higher up, in the region of the fifth dorsal segment, are uninfluenced by caudal analgesia, while the opposing parasympathetic fibres from the sacral plexus below are paralysed.

Successful caudal analgesia in the labouring patient is therefore aimed at securing unopposed and painless contractions of the uterine fundus, acting upon a completely paralysed and insensitive cervix and birth canal. These conditions seem very suitable for dealing with the problem of either inert uterine function or cervical dystocia, or a combination of these two conditions, and the principle has been adopted in the management of the labours described below.

\section{Methods Used}

The technique of continuous caudal analgesia used in this series closely followed that described by. Hingson and Edwards (1943). With the patient lying in the left lateral position, a malleable caudal needle was introduced into the sacral canal and connected by a length of fine pressure-tubing, with a 10-ml. syringe and two-way tap interposed, to a bottle of $1.5 \%$ piperocaine hydrochloride ("metycaine ") in RingerLocke solution. The malleable-needle technique was adopted in preference to the indwelling-catheter method for several reasons. In the first place, suitable nylon catheters were not easily obtained, and complications have been reported from time to time with "polythene" catheters. The risk of introducing infection seemed greater with any catheter technique, together with the added risk of tubing fracture. Furthermore, it is doubtful whether polythene catheters can be sterilized with sufficient certainty to insert into the extradural space with complete safety.

The malleable-needle technique proved completely satisfactory, and the requisite apparatus can now be obtained from Messrs. Thackray, Ltd. It was always ready for use, being autoclaved in a small drum together with the necessary drapings.

Analgesia was induced when labour had been prolonged beyond 48 hours owing either to an intrinsic failure of uterine function or to cervical dystocia without any evidence of cephalo-pelvic disproportion.

A preliminary vaginal examination was always made before caudal analgesia, to assess carefully the stage to which labour had progressed and to ensure that the cervix had reached at least one-third dilatation. Hingson and Edwards state that this degree of dilatation is essential, and failure to observe this rule may result in the inhibition of uterine contractions. It is also emphasized that this method 